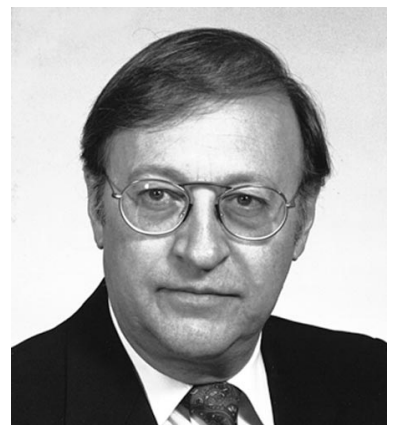

\section{What kind of future are we looking for?}

During meetings, many situations occur, many anecdotes are told, and from time to time we see the evolution of our discipline and often can perceive where the discipline is aiming.

There are all kinds of meetings. Scientific or technical meetings where we meet well-established scientists and engineers. Technical meetings more oriented toward technical development and applications. Recently, a new type of meeting where optics industry people meet and discuss their common interests has started and is growing rapidly: we call this optics clustering.

In all these kinds of meetings, companies have booths for interviewing young scientists and engineers who want to make a career in our discipline or others who want to seek opportunities or come back to the discipline. These booths are growing and many companies present new strategies to attract all those persons looking for the best offer that will fulfill their aims. It is marvelous to see all the opportunities occurring now, and we see people going from one business to another, selling their know-how and experience at the best possible price.

However, since our discipline is growing so rapidly, it becomes a real challenge to find the exact person to fulfill each company's needs. Human resource directors have to fight strongly in order to attract people to their businesses. As we know, choosing optics as a discipline was seen not long ago as a crazy idea. Scientists and engineers who were saying that optics would become very important were perceived as dreamers. Then it was difficult to attract youths in this area. Now, since development of the optics industry is going so fast, it is almost impossible to find appropriate candidates with the right diploma to respond to our industry needs.

Now we are facing a new danger. Businesses cannot wait for the graduation of those who came late to the discipline. Companies use tactics and give gifts to attract people in such a way that they will sign before graduation. We are now facing the fact that newly trained scientists and engineers are recruited and start to work before receiving their diplomas. We are facing the fact that businesses that need technical specialists decide to offer jobs and let the students think that they will get their degree through part-time studies. We also see graduate students leaving before the end of their degree program, master's or $\mathrm{PhD}$, to take a job, thinking that they will be considered as master's or PhD scientists.

Unfortunately it is now true that businesses will consider people as highly valuable scientists or engineers without their postgraduate diploma, or even without their bachelor's degree. It is presently very nice since we are in the most prosperous era that we ever had. What will happen to them when this prosperous cycle ends? What will happen to them when they will find out that they will never be able to get their degrees? Short-sighted companies will put those specialists in a very strange situation. Our discipline, and the development that the world needs for tomorrow, does not deserve this situation.

There is also another problem arising, which is that it is more and more difficult to recruit good students for graduate studies. We will probably face a lack of researchers and developers as our discipline is put in the forefront of the superb development that the world is benefiting from nowadays. In some places, businesses are recruiting professors who really must be at universities to train the people the businesses need.

Without professors doing training research, and without sufficient graduate students, where will our discipline go?

At the last SPIE meeting in San Diego, during the student reception, we found that students are hesitating between taking a job now and waiting to get their degree before taking a job. I was pleased to see companies there who were urging students to get their degree first and explaining that this is the only way to keep a strong industry in any discipline.

To conclude I would express my hope that many companies will go in this direction and urge young scientists and engineers to complete their degrees before thinking of getting a job. This will preserve our industry and will help to maintain the rapid growth we are seeing in our discipline. 